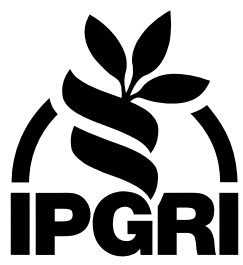

\title{
Is oxidative stress involved in the loss of neem (Azadirachta indica) seed viability?
}

\author{
Moctar Sacandé ${ }^{1,2,4^{*}}$, Folkert A. Hoekstra ${ }^{2}$, Adriaan C. van Aelst ${ }^{3}$ and C.H. Ric De Vos ${ }^{4}$ \\ ${ }^{1}$ Centre National de Semences Forestieres, BP 2682, Ouagadougou, Burkina Faso; ${ }^{2}$ Laboratory of Plant \\ Physiology, Department of Plant Sciences, Wageningen University, Arboretumlaan 4, 6703 BD Wageningen, the \\ Netherlands; ${ }^{3}$ Laboratory of Experimental Plant Morphology and Cell Biology, Department of Plant Sciences, \\ Wageningen University, Arboretumlaan 4, 6703 BD Wageningen, the Netherlands; ${ }^{4}$ Centre for Plant Breeding and \\ Reproduction Research, P.O. Box 16, 6700 AA Wageningen, the Netherlands
}

\begin{abstract}
Neem (Azadirachta indica) is a valuable multipurpose tree of tropical arid and semi-arid regions. The use of its seeds is hindered by their short storage longevity. The possible causes of rapid loss of viability were investigated on different seed lots during exposure to $32 \%$ and $75 \% \mathrm{RH}$ at $20^{\circ} \mathrm{C}$. Within 6 months the seeds almost lost germinability at $75 \% \mathrm{RH}$, whereas at $32 \% \mathrm{RH}$ viability decreased only slightly. On rehydration, the axis cells from nongerminable seeds had lost turgor, whereas those from viable seeds were turgescent as visualized by low temperature scanning electron microscopy images of fractured axes. Glutathione oxidation status was used to estimate oxidative stress during storage. Oxidative stress was much higher at $75 \% \mathrm{RH}$ storage than at $32 \%$ $\mathrm{RH}$, mainly caused by the rapid loss of reduced glutathione at $75 \% \mathrm{RH}$. Oligosaccharides and phospholipids decreased, and free fatty acids increased during storage at the high $\mathrm{RH}$ but remained at a constant level at the low $\mathrm{RH}$. However, the degree of fatty acid unsaturation between viable and nonviable seed lots was similar. During the (slow) dehydration of fresh seeds, total glutathione, oligosaccharides and phospholipids accumulated, particularly in the initially more hydrated seeds. We interpret this accumulation as a postmaturation process associated with acquisition of the capability for long-term survival in the dry state. The mass ratio of oligosaccharides to sucrose was 0.19 on
\end{abstract}

*Correspondence: Laboratory of Plant Physiology,

Wageningen University, Arboretumlaan 4,

6703 BD Wageningen, The Netherlands

Fax: +31-317-484740

Email: moctar.sacande@algem.pf.wau.nl average in dehydrated neem seeds. The data suggest that the storage behaviour of neem seeds has features that characterize it as orthodox.

Keywords: Azadirachta indica, glutathione, oxidative stress, phospholipids, seed viability, storage, sugars

\section{Introduction}

The seeds of most plant species are shed in a partly dehydrated state and can survive further drying to low moisture contents (MCs). Such dry seeds are usually able to survive for long periods of time. This type of storage behaviour has been designated as orthodox (Roberts, 1973). In contrast, seeds that are readily damaged by drying and, in addition, often sensitive to low temperatures have been denoted as recalcitrant (Roberts, 1973; Roberts and Ellis, 1989). Seeds that have a lethal limit of dehydration falling between these two categories are referred to as intermediate and can generally be stored for intermediate periods (Ellis et al., 1990, 1991, and references therein). Intermediate seeds survive drying to moderately low MCs and are often injured by low temperatures. Because of the sensitivity to desiccation and/or low temperatures, recalcitrant and intermediate seeds have a relatively short life span.

Neem (Azadirachta indica A. Juss.) is an important multipurpose tropical tree species, but use of its seeds for propagation purposes is hampered by its difficult storage behaviour. Neem seed storage has variously been described as recalcitrant, intermediate, and orthodox. Germinability of seeds is reduced during 
drying, and seed longevity does not exceed a few years under optimal conditions (reviewed by Hong et al., 1996; Poulsen, 1996; Hong and Ellis, 1998).

In desiccation-sensitive seeds, drying increases the production of reactive oxygen species (ROS) such as hydrogen peroxide and superoxide (Leprince et al., 1990, 1994). Production of ROS has been demonstrated for some recalcitrant temperate tree seeds (FinchSavage et al., 1994) and the intermediate papaya seeds (Magill et al., 1993). ROS formed during drying have been associated with damage to cellular constituents such as proteins, DNA, and membranes, which may ultimately result in cell death (Benson, 1990). Oxidative stress has also been shown to take place during storage of seeds (Hendry et al., 1992) and to be involved in the viability loss of entire plants under environmental stress from chilling, freezing, or exposure to environmental pollution (Bowler et al., 1992). Seeds have several antioxidant systems that may help to prevent oxidative damage. These systems include the enzymes superoxide dismutase, ascorbate peroxidase and glutathione reductase and several nonenzymatic antioxidant compounds like reduced glutathione (GSH), tocopherol and ascorbic acid (Hendry et al., 1992). However, under stress conditions, oxidation may still occur if the cellular antioxidant systems fail to control oxidative injury (Benson, 1990; De Vos et al., 1994). This may be the cause (or effect) of deterioration in seeds (Wilson and McDonald, 1986).

Non-protein compounds with an active sulfhydryl (SH-) group like GSH can protect $\mathrm{SH}$-groups in proteins from harmful oxidation, forming intramolecular disulfide bridges (S-S) (Navari-Izzo et al., 1997). During dry storage of plant systems, GSH can be oxidized as a result of ROS formation, forming the glutathione disulfide GSSG that can be converted back to GSH after rehydration (Benson, 1990; De Vos et al., 1994; Kranner and Grill, 1996). Thus, the increase in the ratio of GSSG to total glutathione $(\mathrm{GSH}+\mathrm{GSSG})$, i.e. the glutathione redox status, reflects oxidative stress in seeds. Other indices of oxidative damage during drying and storage are an increase in ion leakage resulting from membrane breakdown and changes in the content and composition of membrane lipids (Wilson and McDonald, 1986; Benson, 1990). Decreases in phospholipid content and in the level of unsaturation of the esterified acyl chains, and increases in free fatty acid content are associated with oxidative stress (Van Bilsen and Hoekstra, 1993; Van Bilsen et al., 1994).

Desiccation and storage survival may also depend on the ability of seeds to produce sugars that stabilize biomembranes (Crowe et al., 1992) and proteins (Carpenter and Crowe, 1989). The sugars have been hypothesized to replace the lost water by hydrogen bonding to the membrane lipid polar headgroups and the proteins, thus keeping the native structure intact
(Crowe et al., 1992; Wolkers et al., 1998). Orthodox seeds generally have an elevated proportion of oligosaccharides to the total amount of soluble sugars, whereas recalcitrant seeds usually lack these oligosaccharides or have low mass ratios of oligosaccharides to total soluble sugars (Steadman et al., 1996). Slow drying of seeds can increase the level of these oligosaccharides and improve desiccation tolerance and storage longevity (Sanhewe and Ellis, 1996a,b; Sinniah et al., 1998; Wolkers et al., 1999). The content and concentration of protective sugars in seeds may change during storage due to metabolic activity depending on seed MC and storage temperature.

In the present paper we investigated whether the ageing pattern and compositional characteristics of neem seeds from Burkina Faso may be associated with a specific type of storage behaviour. For this purpose the changes in viability and ultrastructure were analyzed during drying and storage at two different MCs. The glutathione oxidation status as a measure of oxidative stress was determined, and the compositional changes in phospholipids and sugars were measured. The data are discussed in relation to the reputedly intermediate storage behaviour of neem seeds.

\section{Materials and methods}

\section{Plant material}

Neem seeds were harvested at Ouagadougou (Ouaga) and Bobo Dioulasso (Bobo)-two different locations in Burkina Faso. Yellow fruits were picked by hand from more than 20 selected adult trees from 30 -year-old plantations. Seed preparation was carried out on the day of harvest. Fruits were soaked in water and then rubbed with sand. After depulping, the seeds were cleaned and dried in the shade on a grid for 2 days. Seeds surrounded by an intact endocarp were then collected and sent to Wageningen, the Netherlands, in cotton packets, arriving within 7 days after seed preparation.

Seeds were sampled and exposed to two relative humidities (RH) obtained above saturated salt solutions with circulating air at $20^{\circ} \mathrm{C}\left(\mathrm{CaCl}_{2} \cdot 6 \mathrm{H}_{2} \mathrm{O}\right.$ for $32 \% \mathrm{RH}$, and $\mathrm{NaCl}$ for $75 \% \mathrm{RH}$ ). After storage at these RHs for the appropriate periods, sub-samples from each lot were germinated or stored at $-80^{\circ} \mathrm{C}$, until use.

\section{Moisture content and germination}

Three replicates of five embryos (seeds with pericarp removed) were weighed, dried at $103^{\circ} \mathrm{C}$ for $17 \mathrm{~h}$ and then weighed again for the determination of MCs, expressed as a percentage of the fresh weight (FW) (ISTA, 1993). 
The viability of seeds was defined as the germination capacity. Two replicates of 50 seeds were soaked for $4 \mathrm{~h}$ at $30^{\circ} \mathrm{C}$ (50 seeds in $100 \mathrm{ml}$ of water; no supplementary aeration) and then placed on wet filter paper in germination boxes that were placed in the light for $8 \mathrm{~h} / \mathrm{d}$ at $30^{\circ} \mathrm{C}$ and in the dark for $16 \mathrm{~h} / \mathrm{d}$ at $20^{\circ} \mathrm{C}$. The seeds were scored twice a week until all viable seeds had germinated. A seed was scored as germinated when a radicle of $30 \mathrm{~mm}$ had emerged (ISTA, 1993).

\section{Analysis of non-protein thiols and disulfides}

\section{Preparation of seed material and extracts}

Seeds that were initially stored at $-80^{\circ} \mathrm{C}$ were lyophilized for $72 \mathrm{~h}$ and then kept in a desiccator under vacuum at room temperature until analysis. This lyophilization was necessary to avoid SH-group oxidation during the extraction of non-protein (i.e. acid-soluble) thiols (cf. De Vos et al., 1992). All extraction steps were performed at $0-4^{\circ} \mathrm{C}$. We used a modification of the method of De Vos et al. (1994) for determining non-protein thiols and disulfides. Briefly, about $0.5 \mathrm{~g}$ of lyophilized embryos was homogenized in triplicate in $20 \mathrm{ml}$ of an ice-cold solution of $5 \mathrm{mM}$ diethylenetriaminepentaacetic acid (DTPA) in 5\% $\mathrm{w} / \mathrm{v}$ sulfosalicylic acid (SSA), using an UltraTurrax homogenizer operating at maximum speed $(3 \mathrm{~min}$ ). The extracts were placed on ice for at least $10 \mathrm{~min}$ to allow proteins to precipitate. The extracts were then centrifuged twice in an Eppendorf centrifuge at maximum speed for $3 \mathrm{~min}\left(4^{\circ} \mathrm{C}\right)$ to remove the precipitated protein, and the supernatants were put on ice for subsequent analyses.

\section{Assay of acid soluble SH-groups}

Total non-protein thiols in the extracts were determined with $6 \mathrm{mM}$ 5,5'-dithiobisnitrobenzoic acid (DTNB, Ellman's reagent). After mixing $300 \mu \mathrm{l}$ of each supernatant with $630 \mu \mathrm{l}$ of $0.5 \mathrm{M} \mathrm{K}_{2} \mathrm{HPO}_{4}$ (giving a $\mathrm{pH}$ of approximately 7.0) and $25 \mu \mathrm{l}$ of the DTNB solution, the absorbance was read after $1 \mathrm{~min}$ at 412 $\mathrm{nm}$ (absorption coefficient $=13,600)$ (Ellman, 1959). The absorbance was corrected for DTNB using the extraction buffer (SSA/DTPA) instead of supernatant. Duplicate assays were performed for each extract. The content of total non-protein $\mathrm{SH}$-groups (including GSH) was calculated on the basis of embryo dry weight (DW).

\section{Assay of GSH and GSSG}

Both total glutathione (GSH + GSSG) and GSSG were assayed by an enzymatic cycling method with NADPH and GSSG-reductase (EC 1.6.4.2.; Sigma type III from baker's yeast) at $35^{\circ} \mathrm{C}$. The reactions involved in this cycling method have been outlined in detail by
Anderson (1985). Total glutathione (GSH + GSSG) and GSSG contents were determined separately, and the GSH content was calculated by subtracting the amount of GSSG from the total glutathione level. The contents in the acid supernatants were calculated from standard curves prepared with a standard solution of $0-20 \mu \mathrm{M}$ GSSG in SSA/DTPA.

For the determination of total glutathione, $100 \mu \mathrm{l}$ of DTNB, $50 \mu \mathrm{l}$ of supernatant, $100 \mu \mathrm{l}$ of a $2.1 \mathrm{mM}$ NADPH solution, and $750 \mu \mathrm{l}$ of a $0.143 \mathrm{M}$ phosphate buffer, containing $6.3 \mathrm{mM}$ DTPA, pH 7.5, were sequentially pipetted into a 1-ml cuvette. Then, $25 \mu \mathrm{l}$ of an appropriately diluted solution of GSSGreductase in the buffer was added and rapidly mixed, and the increase in absorbance was followed at 412 $\mathrm{nm}$. For the GSSG determination, the SH-groups (including GSH) in the embryo extracts were derivatized (for at least $3 \mathrm{~h}$ ) with 2-vinylpyridine, immediately after the centrifugation steps, to exclude any further oxidation, as follows. Sequentially, $200 \mu \mathrm{l}$ of supernatant was mixed with $4 \mu \mathrm{l}$ of 2-vinylpyridine and $20 \mu \mathrm{l}$ of $50 \%(\mathrm{w} / \mathrm{w})$ triethanolamine (final $\mathrm{pH}$ $6-7)$ to remove the $\mathrm{SH}$-groups from the extract. This derivatization step was used for both the GSSG standard curve and GSSG analyses of extracts in the same way as indicated for total glutathione.

\section{Analysis of lipids}

Five embryos of each lyophilized seed sample were cut into pieces and mixed well. For extraction and determination of lipids the methods described by Hoekstra et al. (1989) were utilized. In duplicate, 100 $\mathrm{mg}$ of the granulated sample was homogenized with a mortar and pestle and a little sand in $20 \mathrm{ml}$ chloroform:methanol $(2: 1, \mathrm{v} / \mathrm{v})$ containing internal standards for phospholipids and triglycerides $(1.5 \mathrm{mg}$ diheptadecanoylphosphatidylcholine and $30 \mathrm{mg}$ triheptadecanoin, respectively). The homogenate was centrifuged and the supernatant washed with 0.2 volumes of $0.9 \% \mathrm{NaCl}$ solution. After phase separation the chloroform layer was collected, dried by passage over anhydrous $\mathrm{Na}_{2} \mathrm{SO}_{4}$ and vacuum evaporated. The residue was resuspended in $1 \mathrm{ml}$ chloroform and separated into a neutral and a polar lipid fraction by passing the material over a SEP-PAK silica cartridge (Waters Associates, Milford, MA, USA, catalog no. 51900). The neutral lipids were eluted with $20 \mathrm{ml}$ chloroform, followed by elution of the polar lipids with $30 \mathrm{ml}$ methanol. Transmethylation of the lipid fractions was carried out with $0.3 \mathrm{M} \mathrm{KOH}$ in methanol for $15 \mathrm{~min}$ at $70^{\circ} \mathrm{C}$ with vigorous shaking. After cooling, the methylated fatty acids were phase separated to hexane and dried over anhydrous $\mathrm{Na}_{2} \mathrm{SO}_{4}$ before GC analysis. The amount of phospholipids and neutral lipids was determined by comparing the total peak surface of methyl esters with that of the heptadecanoic methyl ester (Hoekstra et al., 1989). 
For the analysis of free fatty acids, the embryos $(100 \mathrm{mg}$ ) were homogenized in the presence of $0.1 \mathrm{mg}$ heptadecanoic acid as the internal standard. After following the procedures outlined above, the neutral lipid fraction containing the free fatty acids was separated on TLC plates using hexane: diethylether:acetic acid (80:20:1, v/v/v) as the developing solvents. After the plates were sprayed with $0.1 \%$ 8-anilino-1-naphthalene sulfonic acid in methanol and inspected with UV light, the free fatty acid band was scraped off and methylated using freshly prepared diazomethane in diethylether.

Fatty acid methylesters were analyzed on a Shimadzu GC8A GC, equipped with a $30 \mathrm{~m} \mathrm{J \& W}$ DB225 megabore column (J\&W Scientific, Folsom, CA, USA), coupled to a Spectra Physics SP4100 integrator. Identification was done by comparison with standards and GC-MS analysis as described by Van Bilsen et al. (1994).

\section{Carbohydrate analysis}

In duplicate, approximately $100 \mathrm{mg}$ of each of the same lyophilized samples was homogenized with a mortar and pestle in $10 \mathrm{ml} 80 \%$ methanol containing $10 \mathrm{mg}$ melezitose as the internal standard. The samples were kept at $76^{\circ} \mathrm{C}$ in a water bath for $15 \mathrm{~min}$ to extract soluble carbohydrates and to inactivate enzymes. Subsequently, the methanol was evaporated in a Speedvac (Savant Instruments Inc., Farmingdale, NY, USA). The samples were then suspended in $10 \mathrm{ml}$ of milli-Q water. After centrifugation in an Eppendorf centrifuge for $3 \mathrm{~min}$ at maximum speed $(15,000 \mathrm{rpm})$, the supernatants were diluted 50 -fold with $\mathrm{H}_{2} \mathrm{O}$ for HPLC analysis. Carbohydrates were separated with a Dionex HPLC system (Dionex Corporation, Sunnyvale, CA, USA) equipped with a pulsed amperometric detector. For the separation of carbohydrates, a Carbopac PA-1 column with guard column was used, operated at $30^{\circ} \mathrm{C}$. A $50-200 \mathrm{mM}$ gradient of $\mathrm{NaOH}$ in water was used as the eluent, and $1.1 \mathrm{M}$ sodium acetate in $100 \mathrm{mM} \mathrm{NaOH}$ was used to clean the column after each run. The data were analyzed using a Spectra Physics integrator model SP 4400 and Spectra Physics software (Labnet, Chromdat, San Jose, CA, USA). Identification of carbohydrate peaks was by comparison with retention times of standard solutions in two different elution programmes (the $50-200 \mathrm{mM} \mathrm{NaOH}$ gradient or with $100 \mathrm{mM} \mathrm{NaOH}$ ).

\section{Low temperature scanning electron microscopy} (LTSEM)

After $4 \mathrm{~h}$ of soaking in water at $30^{\circ} \mathrm{C}$ (as for the germination assay), seeds were incubated on wet filter paper for $20 \mathrm{~h}$ at $30^{\circ} \mathrm{C}$, and axes were subsequently isolated and mounted on stubs with conductive carbon cement (Leit-C, Neubauer
Chemikalien, Münster, Germany). The stubs were placed on a specimen holder that was plunged into liquid nitrogen $\left(-196^{\circ} \mathrm{C}\right)$. The stubs with the frozen axes were transferred to a cryo-transfer unit (CT 1500 $\mathrm{HF}$, Oxford Instruments, Oxon, UK), consisting of a cryo-preparation chamber at high vacuum $\left(10^{-6} \mathrm{~Pa}\right)$ attached to the LTSEM, and a cryo-stage inside the microscope. The axes were placed inside the cryochamber at $-85^{\circ} \mathrm{C}$, kept there for $2 \mathrm{~min}$ to sublimate the contaminating water vapor, and then crosssectioned with a cold sharp knife. After sputtercoating with $3 \mathrm{~nm}$ platinum, the coated specimen was placed inside the LTSEM (JEOL, model $6300 \mathrm{~F}$, Tokyo, Japan) and observed at 1-5 kV. The temperature of the specimens inside the LTSEM was kept at $-180^{\circ} \mathrm{C}$.

\section{Results}

\section{Equilibrium moisture contents and germination capacity of seeds}

Seeds from Ouagadougou and Bobo Dioulasso initially germinated at $>90 \%$. Under defined conditions of $\mathrm{RH}$ at $20^{\circ} \mathrm{C}$, fresh seeds reach equilibrium MCs after 3-4 weeks of exposure (Sacandé et al., 1998). For the RHs of $32 \%$ and $75 \%$ at $20^{\circ} \mathrm{C}$, equilibrium MCs were $5.5 \%$ and $11.7 \%$ (FW basis), respectively. Seed germinability was followed over the 26 weeks of exposure to the two RHs (Fig. 1). Seeds from both sources behaved similarly. High germinability was maintained during the first 6 weeks of exposure to $75 \% \mathrm{RH}$, followed by a decrease to $<20 \%$ at 26 weeks. At $32 \% \mathrm{RH}$, germinability dropped to approximately $70-80 \%$ after the first 3-6 weeks and then slowly decreased to $60-70 \%$ over the next 20 weeks of storage.

\section{Non-protein thiols during dehydration and storage}

As thiols are sensitive to oxidation, it is possible that they become oxidized during extraction, resulting in erroneous thiol-disulfide values (De Vos et al., 1994). To determine whether such artefactual oxidation occurred, seeds were homogenized in SSA + DTPA in the presence and absence of an internal GSH standard and subsequently analyzed for both GSH and GSSG. A high recovery of the GSH added (96\%) was obtained, which indicated that the extraction and analysis procedures were correct and that the amounts of GSH and GSSG measured corresponded to the amounts actually present in the seeds.

The non-protein thiol contents in the embryos comprise the amounts of GSH and a number of other compounds with SH groups (e.g. cysteine). The changes in content of these thiol compounds were followed during exposure of the seeds to $32 \%$ and 


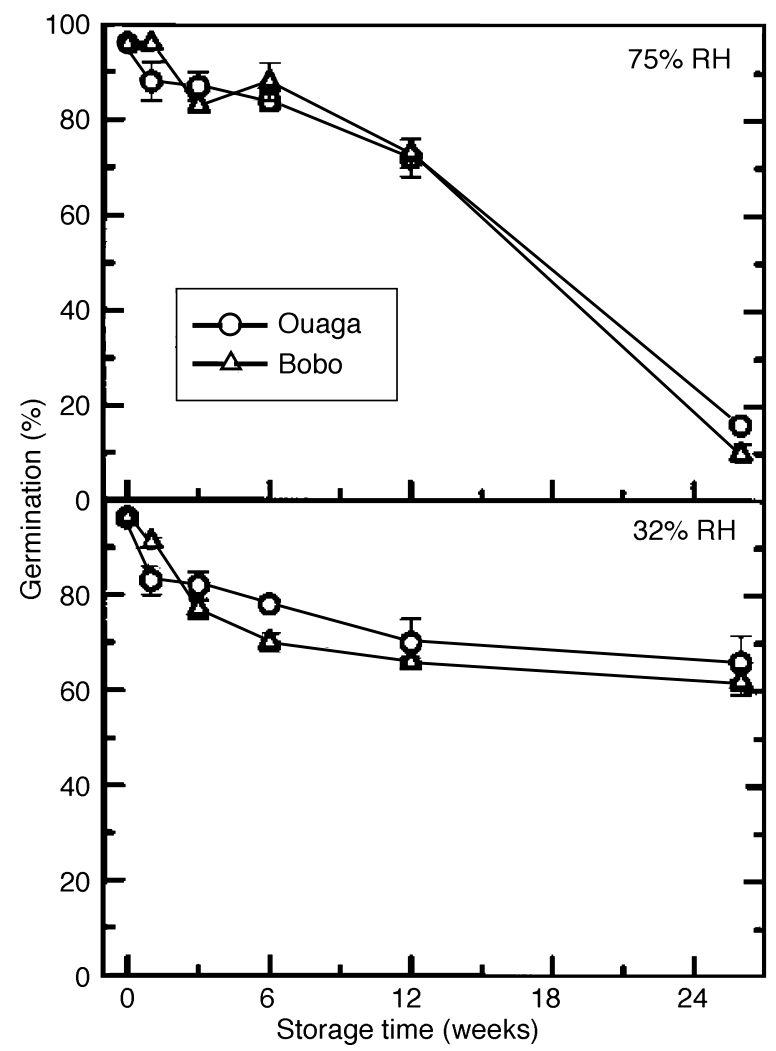

Figure 1. Germinability of neem seeds from Ouagadougou (Ouaga) and Bobo Dioulasso (Bobo), Burkina Faso, after $0-26$ weeks of storage at RHs of $75 \%$ (11.7\% MC, FW basis) and $32 \%$ (5.5\% MC, FW basis), at $20^{\circ} \mathrm{C}$. Each data point is the mean percentage of germinated seeds ( 250 seeds). SD is represented when larger than the symbols. Data are significantly $\left(\begin{array}{ll}P & 0.05\end{array}\right)$ different when they diverge by $15 \%$ or more $\left(\chi^{2}\right.$ test).

$75 \% \mathrm{RH}$ at $20^{\circ} \mathrm{C}$ (Fig. 2). Analyses showed significant initial differences in the content of total non-protein thiols between the seed sources. The embryos from the seed lot with the highest MC (from Bobo; 25.0\% $\mathrm{MC}$ ) had an initially lower amount of $\mathrm{SH}$-containing compounds than those that were drier at the onset of the exposure to the RHs (from Ouaga; $14.8 \% \mathrm{MC}$ ). Other, more immature samples that were more hydrated at the onset of drying (41.3\% MC) had even lower initial amounts of $\mathrm{SH}$-compounds (data not shown). During drying to equilibrium MCs (first 3 weeks of storage), the initially low contents in the Bobo seeds rose to levels that were of the same order as those in the initially drier (Ouaga) samples (Fig. 2). Upon further storage, the thiol contents changed depending on the equilibrium $\mathrm{MC}$ that the seeds had attained. The high moisture condition $(75 \% \mathrm{RH}$, giving $11.7 \% \mathrm{MC}$ ) led to a rapid decrease in content during storage for both seed sources, whereas in the low moisture condition ( $32 \% \mathrm{RH}$, giving $5.5 \% \mathrm{MC}$ ),

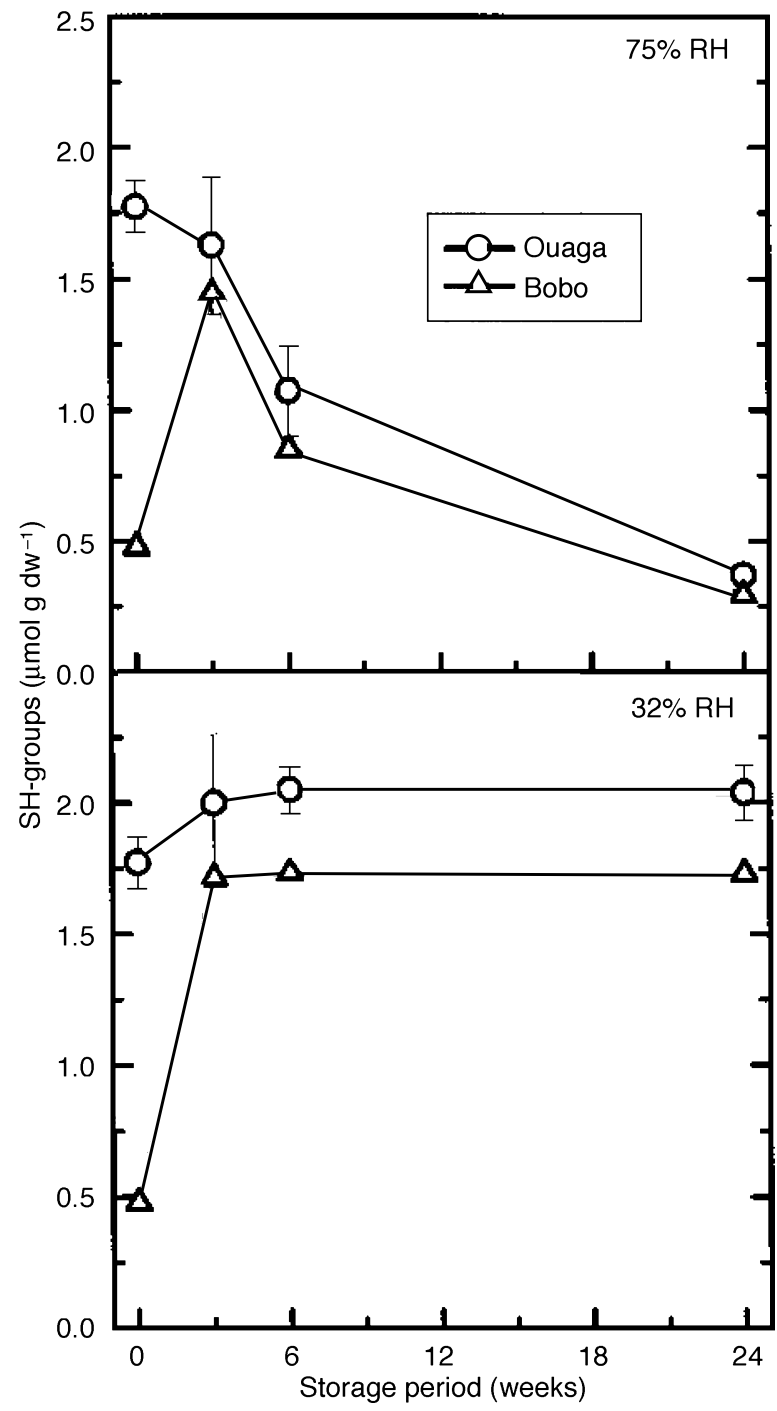

Figure 2. Effect of storage on total non-protein SH-content of neem embryos. Seeds from Ouaga and Bobo were stored for 24 weeks at $20^{\circ} \mathrm{C}$ at $32 \%$ or $75 \% \mathrm{RH}$. Each data point is the mean of three replicates from extracts of five embryos. $\mathrm{SD}$ is represented when larger than the symbols.

the contents stabilized after 3 weeks when the seeds had reached equilibrium MC. Other seed sources displayed essentially the same pattern (data not shown) as those shown in Fig. 2.

\section{Glutathione redox status}

A very similar pattern of changes in GSH content with drying and further dry storage was observed (Fig. 3) as found for the total non-protein thiols in Fig. 2. After an initial increase in the content of the originally more hydrated sample, most likely associated with afterripening processes, a decrease in the amount of GSH occurred in the seed lots stored at 


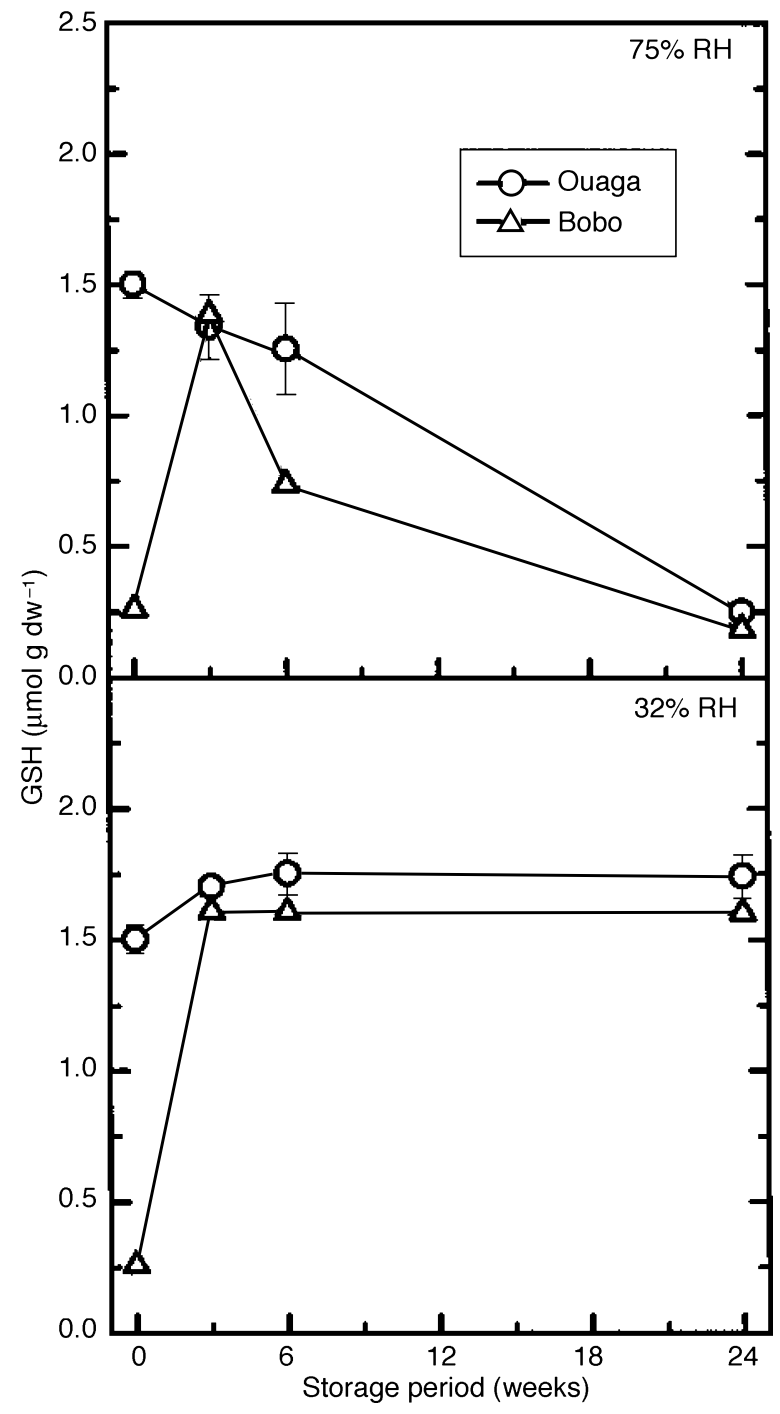

Figure 3. Change in GSH content in embryos during storage of neem seeds from Ouaga and Bobo at $20^{\circ} \mathrm{C}$ at $32 \%$ and $75 \% \mathrm{RH}$. Each data point is the mean of three replicates from extracts of five embryos. SD is represented when larger than the symbols.

$75 \% \mathrm{RH}$, whereas the seed lots stored at 32\% RH had stable amounts during the entire storage period. The amount of GSH during storage under both $\mathrm{RH}$ conditions was slightly less than that of the total of non-protein SH-compounds (Fig. 2) in all extracts, which means that GSH comprised most of the nonprotein thiols present in the seeds. A sample of seeds from green fruits containing the highest water content, had the lowest GSH content at the onset of drying, which increased to values comparable with those initially found in the drier samples from the yellow fruits (data not shown).

The amounts of GSSG increased with the water loss of the samples during the first 3-6 weeks of

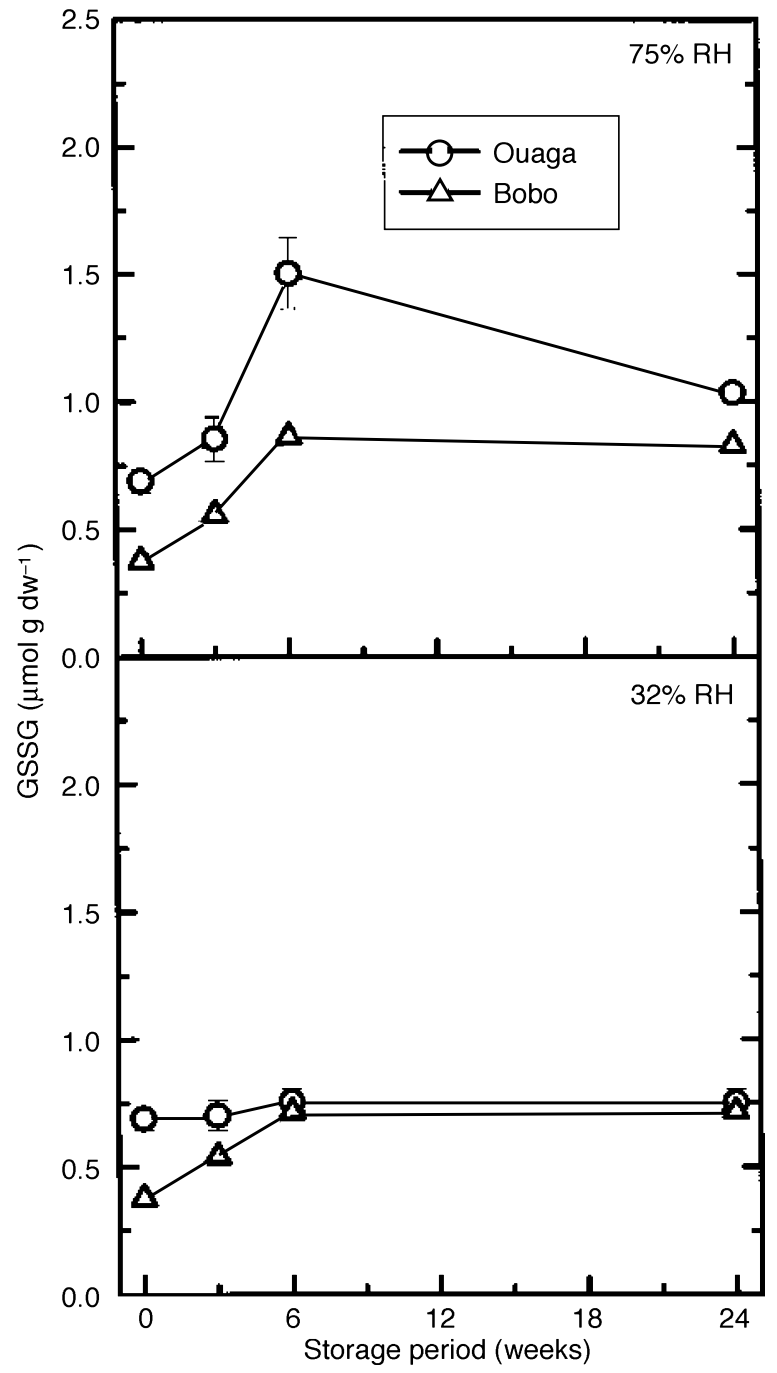

Figure 4. Change in the GSSG content in embryos during storage of neem seeds from Ouaga and Bobo at $20^{\circ} \mathrm{C}$ at $32 \%$ and $75 \% \mathrm{RH}$. Each data point is the mean of three replicates from extracts of five embryos. SD is represented when larger than the symbols.

exposure (Fig. 4). After 6 weeks this increase levelled off, or the GSSG contents slightly decreased (in the case of storage of the Ouaga seeds at $75 \% \mathrm{RH}$ ). For the levels of total glutathione (not shown), this has the following consequences. During the first 3-6 weeks, the increase in GSH in most of the samples and the simultaneous increase in GSSG led to a net increase in the total glutathione levels. However, during further storage at $75 \% \mathrm{RH}$, the decrease in GSH and the more or less stable level of GSSG led to a net loss of total glutathione during storage. During further storage at $32 \% \mathrm{RH}$, the amount of total glutathione did not change much.

The ratio of GSSG to total glutathione can be considered as a measure of the cellular redox status 


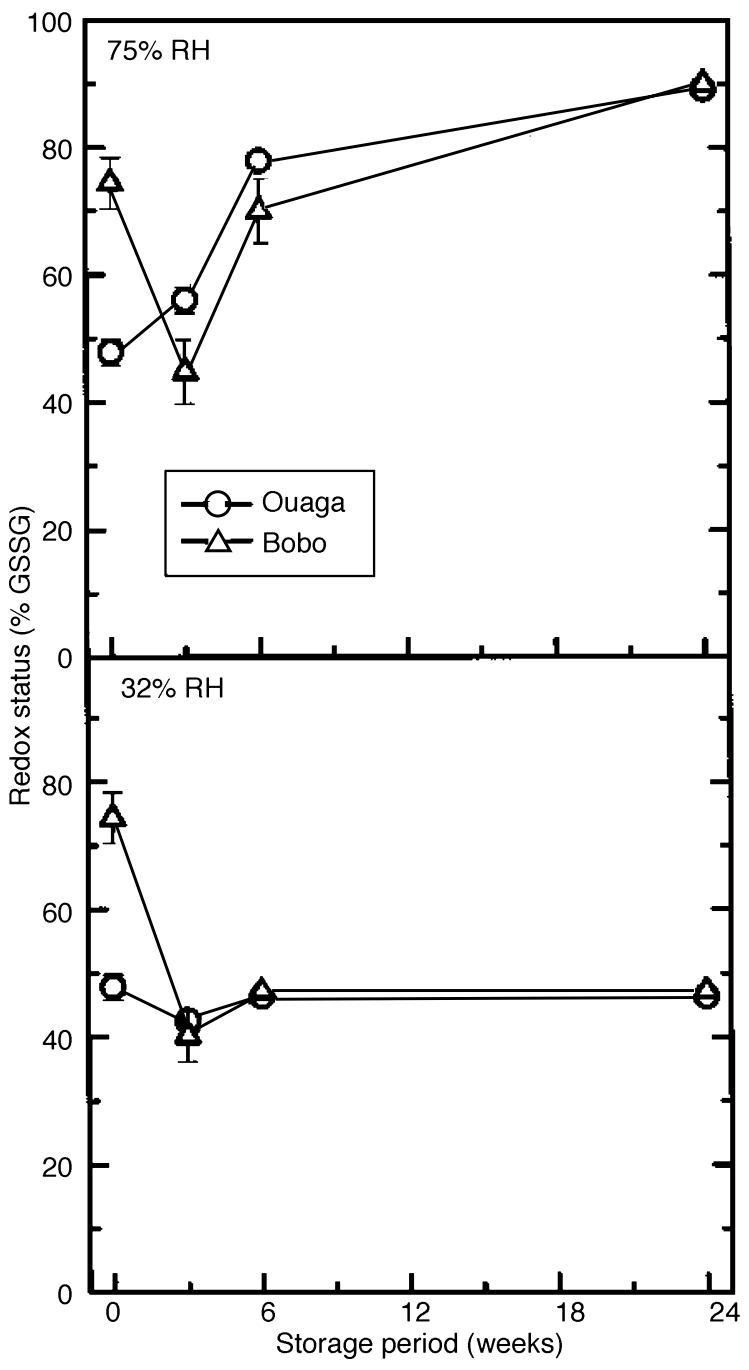

Figure 5. Change in the glutathione redox status [(S-) groups in GSSG expressed as a percentage of (S-) + (SH-) groups in total glutathione] in embryos of neem seeds stored under conditions of $32 \%$ and $75 \% \mathrm{RH}$ at $20^{\circ} \mathrm{C}$. Data give an estimate of oxidative stress and are the means of three replicates from extracts of five embryos. SD is represented when larger than the symbols.
(De Vos et al., 1994; Kranner and Grill, 1996). In the seeds stored at $75 \% \mathrm{RH}$ the proportion of GSSG increased up to $90 \%$ (Fig. 5), which suggests oxidative stress during storage. The initial reduction in this ratio during drying for the wettest seeds can be explained by the fact that the production of GSH, associated with afterripening, occurred at a higher rate than that of GSSG. Under conditions of $32 \% \mathrm{RH}$, the redox status remained stable and low over the storage period. We conclude that the seeds kept at $75 \% \mathrm{RH}$ experienced oxidative stress, whereas those at $32 \%$ RH did not.

\section{Lipids during dehydration and storage}

In an attempt to measure possible increases in lipid peroxidation products over storage as an indication of oxidative damage, thiobarbituric acid reactive substances were measured at $532 \mathrm{~nm}$ according to the method of De Vos et al. (1994). The method did not show significant differences between seeds kept under the different storage conditions (data not shown). This could indicate that there was no peroxidation, or that the lipids did not contain sufficient poly-unsaturated fatty acids to allow detection of changes in absorption at $532 \mathrm{~nm}$.

Table 1 shows the amounts of phospholipids and free fatty acids during dehydration and subsequent storage of the Bobo seed lot (25.0\% initial MC) at $32 \%$ and $75 \% \mathrm{RH}$ and $20^{\circ} \mathrm{C}$. During drying (first 6 weeks of storage), the phospholipid (PL) content increased, particularly when the drying occurred at $32 \% \mathrm{RH}$. This content remained unchanged during the next 18 weeks of storage at 32\% RH. However, at $75 \% \mathrm{RH}$ there was also a breakdown of the phospholipids, associated with an increase in the cellular level of free fatty acids. Compositional analysis of the acyl chains of the phospholipids showed that oleic acid (18:1) was the dominant fatty acid and that there was very little linolenic acid (18:3) present. Slight changes in composition could be observed during drying and storage. At $75 \% \mathrm{RH}$ there was a slight but significant

Table 1. Free fatty acid (FFA) and phospholipid (PL) contents and fatty acid composition of neem seeds from Bobo Dioulasso. The initially fresh seeds had 25.0\% MC (FW basis). Data are means of two extractions. The double bond (DB) index (number of double bonds per acyl chain) is also indicated. Palmitic acid, 16:0; stearic acid, 18:0; oleic acid, 18:1; linoleic acid, 18:2; linolenic acid, 18:3.

\begin{tabular}{|c|c|c|c|c|c|c|c|c|}
\hline \multirow[t]{2}{*}{ Treatment } & \multirow{2}{*}{$\begin{array}{l}\text { FFA- } \\
\text { content } \\
(\mathrm{mg} / \mathrm{g} \mathrm{DW})\end{array}$} & \multirow{2}{*}{$\begin{array}{l}\text { PL- } \\
\text { content } \\
(\mathrm{mg} / \mathrm{g} \mathrm{DW})\end{array}$} & \multicolumn{5}{|c|}{ Mol \% fatty acids in PL } & \multirow{2}{*}{$\begin{array}{l}\text { DB } \\
\text { index }\end{array}$} \\
\hline & & & $16: 0$ & 18:0 & $18: 1$ & $18: 2$ & $18: 3$ & \\
\hline $\begin{array}{l}\text { Fresh, no drying } \\
32 \% \text { RH }\end{array}$ & 0.4 & 5.1 & 21.2 & 8.1 & 50.7 & 17.0 & 2.9 & 0.94 \\
\hline 6 weeks & 0.3 & 10.0 & 20.5 & 8.1 & 51.4 & 18.4 & 1.6 & 0.93 \\
\hline 24 weeks & 0.3 & 10.4 & 21.4 & 6.8 & 54.3 & 16.1 & 1.3 & 0.91 \\
\hline \multicolumn{9}{|l|}{$75 \% \mathrm{RH}$} \\
\hline 6 weeks & 2.1 & 7.7 & 18.3 & 8.8 & 56.0 & 15.4 & 1.5 & 0.91 \\
\hline 24 weeks & 7.2 & 6.4 & 18.7 & 8.2 & 54.5 & 16.5 & 2.1 & 0.94 \\
\hline $\operatorname{LSD}(P=0.05)$ & 2.1 & 1.2 & 1.9 & 0.8 & 2.0 & 2.0 & 0.5 & - \\
\hline
\end{tabular}




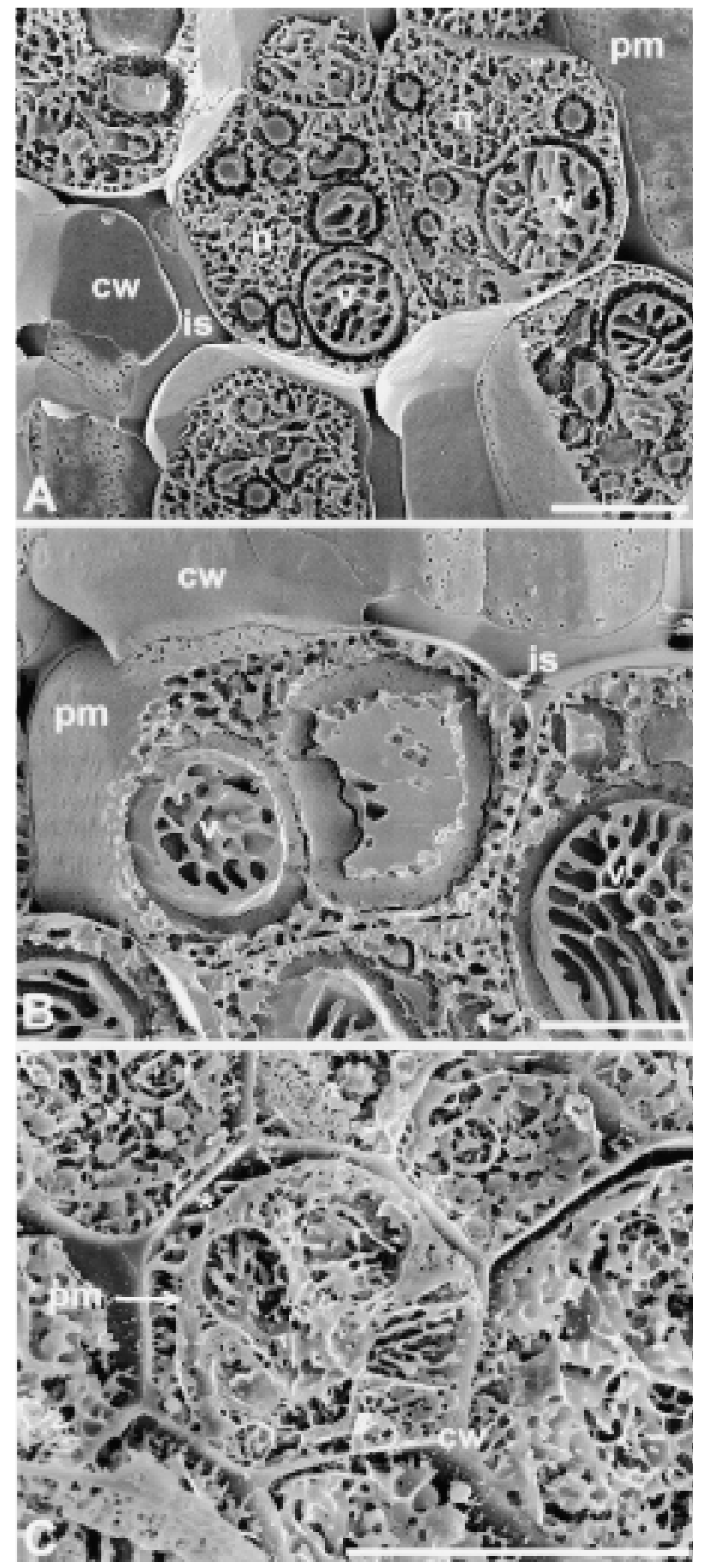

Figure 6. LTSEM micrographs of cryo-fractured axes from neem seeds that were soaked for $4 \mathrm{~h}$ in water at $30^{\circ} \mathrm{C}$, followed by incubation on moist filter paper for $20 \mathrm{~h}$ at $30^{\circ} \mathrm{C}$ : (A) fresh seed; (B) a seed stored for 6 months at $32 \% \mathrm{RH}$ and $20^{\circ} \mathrm{C}$; (C) a seed stored for 6 months at $75 \% \mathrm{RH}$ and $20^{\circ} \mathrm{C}$ (bars $=10 \mu \mathrm{m}) . \mathrm{cw}=$ cell wall, is = intracellular space, $\mathrm{n}=$ nucleus, $\mathrm{pm}=$ plasma membrane, $\mathrm{v}=$ vacuole. Asterisk: space between plasma membrane and cell wall due to turgor loss. decrease in palmitic (16:0) and linolenic acids, and a slight increase in oleic acid compared with the composition of fresh seeds, whereas at $32 \% \mathrm{RH}$ linolenic acid decreased and the amount of oleic acid was higher after 24 weeks. The number of double bonds per acyl chain did not change consistently during storage at any $\mathrm{RH}$ (Table 1). Neutral lipids comprised almost $50 \%$ of the DW, with a considerable similarity in acyl chain composition to that of phospholipids (data not shown). They had low levels (1-2\%) of eicosenoic acid (20:1) and erucic acid (22:1) that were not found in phospholipids. The free fatty acid content did not increase at $32 \% \mathrm{RH}$ storage, but increased considerably at $75 \% \mathrm{RH}$.

\section{Ultrastructural changes of fresh and stored axes}

After $24 \mathrm{~h}$ of water uptake in Petri dishes, fractured cells of isolated axes were inspected by LTSEM. Figure 6A shows that the axis cells from fresh seeds had a turgescent appearance with large vacuoles visible, typical of viable cells. Axis cells from seeds that had been stored for 6 months at 32\% RH and $20^{\circ} \mathrm{C}$ had an appearance similar to those of fresh seeds (Fig. 6B). However, axis cells from seeds stored for 6 months at $75 \% \mathrm{RH}$ had the typical appearance of debilitated cells that had lost turgor (Fig. 6C).

\section{Sugars during dehydration and storage}

Sugar analysis revealed the presence of the oligosaccharides raffinose and stachyose, the disaccharide sucrose, and the monosaccharides glucose and fructose. Figure 7 shows the changes in raffinose, stachyose, and glucose contents with dehydration and storage of the seeds from Bobo. During drying to $5.5 \% \mathrm{MC}$ under conditions of $32 \%$ $\mathrm{RH}$ (first 6 weeks), the contents of the oligosaccharides and glucose increased and then stabilized. The fructose levels were very low throughout (data not shown). However, when the seeds were dried and stored at $11.7 \% \mathrm{MC}$ at $75 \% \mathrm{RH}$, the increases in oligosaccharides and glucose contents were confounded by a decrease that continued over the entire storage period. The amount of sucrose under both conditions of RH was in the range of 6.4 to $9 \%$ of DW during the storage period, with that at $75 \%$ $\mathrm{RH}$ being slightly below that at $32 \% \mathrm{RH}$ (data not shown). The seeds from Bobo had oligosaccharide contents that were low (Fig. 7) compared with those from the three other seed lots that were tested. The average sugar contents in the four seed lots after drying at $32 \% \mathrm{RH}$ (6 weeks storage) were: raffinose, $5.6 \pm 2.6(\mathrm{SD}) \mathrm{mg} / \mathrm{g}$ DW; stachyose, $7.2 \pm 4.0 \mathrm{mg} / \mathrm{g}$ $\mathrm{DW}$; sucrose, $69.0 \pm 19.4 \mathrm{mg} / \mathrm{g}$ DW; glucose, $3.4 \pm 0.7$ $\mathrm{mg} / \mathrm{g}$ DW, with negligible amounts of less than 0.3 $\mathrm{mg} / \mathrm{g}$ DW for fructose. These sugar contents from the 


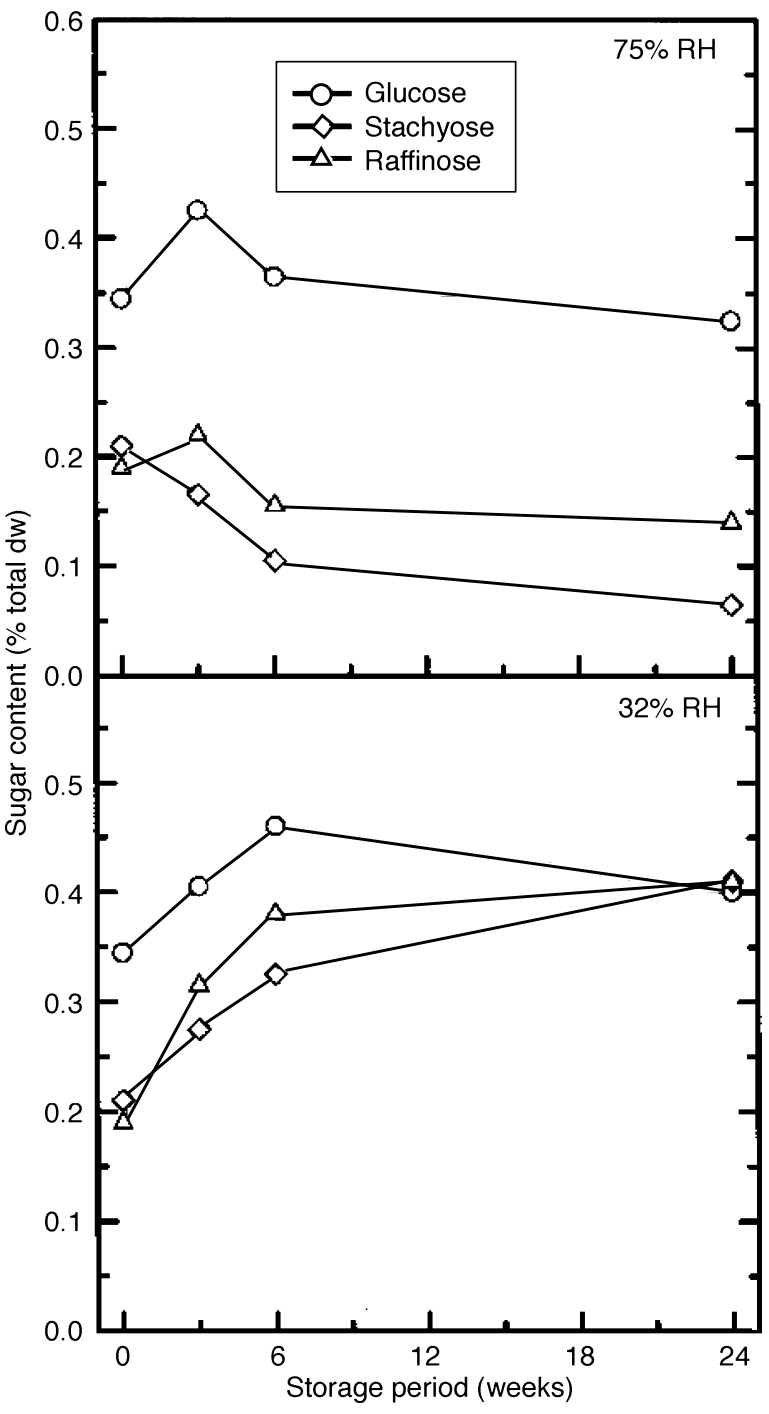

Figure 7. Composition and changes in sugars (glucose, stachyose and raffinose) in embryos of neem seeds from Bobo stored at $32 \%$ and $75 \% \mathrm{RH}$ at $20^{\circ} \mathrm{C}$. Each data point is the mean of two determinations from samples of five embryos.

four lots gave an average oligosaccharide/sucrose mass ratio of 0.19 .

\section{Discussion}

Oxidative stress and compositional changes in a number of neem seed lots from two sources were studied at two humidity regimes, in an attempt to understand the rapid viability loss of neem seeds during drying and storage. Whereas the germination capacity after 6 months at $20^{\circ} \mathrm{C}$ decreased from $96 \%$ to $60-70 \%$ under storage conditions of $32 \% \mathrm{RH}$, germination was less than $20 \%$ after 6 months at $75 \%$ RH (Fig. 1). These data are consistent with other survival data of neem seeds during dehydration and storage (reviewed by Hong et al., 1996; Poulsen, 1996). Seed storage behaviour of neem is controversial. It has been characterized as recalcitrant (Ponnuswamy et al., 1990; Maithani et al., 1989) on the basis of its rapid loss of viability when seeds are stored at $12 \%$ MC (FW basis), which agrees with the rapid deterioration that we observed in seeds stored at 75\% RH ( $11.7 \%$ final MC). Neem seeds have also been categorized as displaying intermediate storage behaviour, because $50 \%$ of seeds have been reported to survive several months of storage after dehydration to water contents as low as 4-6\% (Gaméné et al., 1996; Hong and Ellis, 1998; Sacandé et al., 1996, 1998). This agrees generally with the levels of survival observed in our storage experiments at $32 \%$ $\mathrm{RH}$ (5.5\% equilibrium MC). However, orthodox behaviour has also been claimed on account of more than a decade of successful dry storage at $-20^{\circ} \mathrm{C}$ (Tompsett and Kemp, 1996).

The short longevity of seeds at $11.7 \% \mathrm{MC}$ is not surprising, because deteriorative processes at such water contents may be prominent, particularly in oily seeds. Because $50 \%$ of the DW of neem seeds is in the form of oil (Table 1; Sacandé et al., 2000), the actual water content in the cytoplasm outside the oil will be twice as high as might be expected, i.e. $20.9 \%$ on a FW basis. Under these conditions the cytoplasm is not in the glassy state (Sacandé et al., 2000). It has been suggested that, in general, the rate of deterioration of seeds and pollen is considerably lower when the cytoplasm is in the glassy state than when it is in the liquid state (Sun, 1997; Buitink et al., 1998). At 32\% RH the cytoplasm in neem seeds has been shown to be in the glassy state (Sacandé et al., 2000), supporting this concept.

Our data on the extent of oxidative stress during drying and subsequent storage at $32 \%$ and $75 \% \mathrm{RH}$ (Fig. 5) concur with the existence and absence of cytoplasmic glasses, respectively. Seeds exposed to high RH suffered oxidative stress, whereas dry seeds (32\% RH) did not. The glutathione oxidation status was used to estimate oxidative stress in general (De Vos et al., 1994). In metabolizing tissues GSSG is considered to be reduced immediately back to GSH by the action of glutathione reductase. However, because glutathione reductase presumably cannot be active in seeds in the dry state, desiccated tissues accumulate GSSG depending on the extent of oxidative stress (De Vos et al., 1994; Kranner and Grill, 1996).

Under storage conditions of $75 \% \mathrm{RH}$, a loss of total glutathione was observed - to a lesser extent in GSSG than in GSH - leading to a noticeable shift in the glutathione redox status towards a more oxidized form. In contrast, there was no loss of total glutathione at $32 \% \mathrm{RH}$ storage. Storage at $75 \% \mathrm{RH}$ 
also led to decreases in oligosaccharide and phospholipid contents, which did not occur at 32\% $\mathrm{RH}$.

An interesting observation was made when comparing seed samples of initially different MCs with respect to their glutathione, oligosaccharide and phospholipid contents. The more hydrated samples accumulated these compounds during equilibrium drying (first 3 weeks) to a constant water content (brought about by either $32 \%$ or $75 \% \mathrm{RH}$ ), whereas the initially drier samples already contained elevated amounts of these compounds. We interpret this to result from afterripening (or post-maturation) processes induced by slow drying, during which the seeds become better able to withstand complete water loss. In our opinion, this is a clear indication that neem seeds display typically orthodox rather than recalcitrant behaviour. Although recalcitrant seeds do possess antioxidant mechanisms (reviewed by Pammenter and Berjak, 1999), these mechanisms tend to become insufficiently effective during dehydration, because these seeds cannot down-regulate metabolism in the way that orthodox seeds do.

Loss of seed viability has been linked to increased lipid peroxidation, particularly of the polyunsaturated fatty acids (Wilson and McDonald, 1986), which can lead to disrupted membranes and the associated leakage of endogenous solutes. We were unable to detect signs of such lipid peroxidation when measuring thiobarbituric acid reactive substances. The low levels of poly-unsaturated (18:3) acyl chains in the neutral lipids and phospholipids (Table 1) can explain this because the assay is particularly sensitive to the peroxidation products of the poly-unsaturated lipids. Also, the analysis of the fatty acid composition in the phospholipids does not indicate that lipid peroxidation occurs to any considerable extent during storage at $75 \% \mathrm{RH}$. This observation is in agreement with the results of others (Priestley and Leopold, 1979; Senaratna et al., 1988; Van Bilsen and Hoekstra, 1993; De Vos et al., 1994). However, during storage at $75 \%$ RH free fatty acids in the neem seeds accumulated and the phospholipid content decreased - a phenomenon that has been observed in many other systems during (accelerated) ageing (Priestley and Leopold, 1979; Senaratna et al., 1988; Van Bilsen and Hoekstra, 1993; Van Bilsen et al., 1994). It has been proposed that a mechanism other than peroxidation is responsible for the acyl chain deesterification (Senaratna and McKersie, 1986). The larger free fatty acid accumulation in neem seeds compared with the loss in phospholipid content may be attributed to a contribution of free fatty acids originating from the neutral lipids. The supposition that the lipid changes in the seeds stored at $75 \% \mathrm{RH}$ reduce the barrier properties of the plasma membrane is supported by the LTSEM micrograph (Fig. 6C), showing the loss of turgescence of the axis cells after 6 months under this $\mathrm{RH}$ condition.

The occurrence of di- and oligo-saccharides has been linked with the acquisition of tolerance to desiccation (Horbowicz and Obendorf, 1994) and improvement of storage longevity. Particularly, the mass ratio of oligosaccharides to sucrose has been implicated in these capabilities (Steadman et al., 1996). Neem seeds accumulated oligosaccharides (Fig. 7) in amounts comparable to those found in orthodox seeds. The average mass ratio of oligosaccharide to sucrose of 0.19 for two batches of the seeds from both locations is in the typical range for orthodox seeds. Recalcitrant seeds are generally characterized by mass ratios of oligosaccharides to sucrose of $<0.083$ (Steadman et al., 1996).

Taken together, the dehydration-induced increase in substances that are considered to promote desiccation tolerance, the relatively high oligosaccharide content, and the ability to survive longterm dry storage imply that neem seeds have orthodox rather than intermediate or recalcitrant storage behaviour. Their extreme sensitivity to imbibitional stress (Sacandé et al., 1998) may have contributed to their reputation as being difficult to store. In addition, dehydration histories of the original seed samples may lead to differences in the amounts of protective substances in the dehydrated seeds and might also help to explain variations in the extent to which neem seeds can be successfully stored.

\section{Acknowledgements}

Financial support from the Dutch Organization for the Advancement of Tropical Research (WOTRO) is gratefully acknowledged.

\section{References}

Anderson M.E. (1985) Tissue glutathione. pp.317-323 in Greenwald, R.A. (Ed.) Handbook of methods for oxygen free radical research. Boca Raton, CRC Press.

Benson, E.E. (1990) Free radical damage in stored plant germplasm. pp. 37-68. Rome, International Board of Plant Genetic Resources (IBPGR).

Bowler, C., Van Montagu, M. and Inze, D. (1992) Superoxide dismutase and stress tolerance. Annual Review of Plant Physiology and Plant Molecular Biology 43, 83-116.

Buitink, J., Walters, C., Hoekstra, F.A. and Crane, J. (1998) Storage behaviour of Typha latifolia pollen at low water contents: Interpretation on the basis of water activity and glass concepts. Physiologia Plantarum 103, 145-153.

Carpenter, J.F. and Crowe, J.H. (1989) An infrared spectroscopic study of the interactions of carbohydrates with dried proteins. Biochemistry 28, 3916-3922. 
Crowe, J.H., Hoekstra, F.A. and Crowe, L.M. (1992) Anhydrobiosis. Annual Review of Physiology 54, 579-599.

De Vos, C.H.R., Vonk, M.J., Vooijs, R. and Schat, H. (1992) Glutathione depletion due to copper-induced phytochelatin synthesis causes oxidative stress in Silene cucubalus. Plant Physiology 98, 853-858.

De Vos, C.H.R., Kraak, H.L. and Bino, R.J. (1994) Ageing of tomato seeds involves glutathione oxidation. Physiologia Plantarum 92, 131-139.

Ellis, R.H., Hong, T.D. and Roberts, E.H. (1990) An intermediate category of seed storage behaviour? I. Coffee. Journal of Experimental Botany 41, 1167-1174.

Ellis, R.H., Hong, T.D. and Roberts, E.H. (1991) Effect of storage temperature and moisture on the germination of papaya seeds. Seed Science Research 1, 69-72.

Ellman, G.L. (1959) Tissue sulfhydryl groups. Archives of Biochemistry and Biophysics 82, 70-77.

Finch-Savage, W.E., Hendry, G.A.F. and Atherton, N.M. (1994) Free radical activity and loss of viability during drying of desiccation-sensitive tree seeds. Proceedings of the Royal Society of Edinburgh Section B 102, 257-260.

Gaméné, C.S., Kraak, H.L., Van Pijlen, J.G. and De Vos, C.H.R. (1996) Storage behaviour of neem (Azadirachta indica) seeds from Burkina Faso. Seed Science and Technology 24, 441-448.

Hendry, G.A.F., Finch-Savage, W.E., Thorpe, P.C., Atherton, N.M., Buckland, S.M., Nilsson, K.A. and Seel, W.E. (1992) Free radical processes and loss of seed viability during desiccation in the recalcitrant species Quercus robur L. New Phytologist 122, 273-279.

Hoekstra, F.A., Crowe, L.M. and Crowe, J.H. (1989) Differential desiccation sensitivity of corn and Pennisetum pollen linked to their sucrose contents. Plant Cell and Environment 12, 83-91.

Hong, T.D. and Ellis, R.H. (1998) Contrasting seed storage behaviour among different species of Meliaceae. Seed Science and Technology 26, 77-95.

Hong, T.D., Linington, S. and Ellis, R.H. (1996) Seeds storage behaviour: a compendium. Handbooks for genebanks No 4 . Rome, Italy, International Plant Genetic Resources Institute (IPGRI).

Horbowicz, M. and Obendorf, R.L. (1994) Seed desiccation tolerance and storability: dependence on flatulenceproducing oligosaccharides and cyclitols-review and survey. Seed Science Research 4, 385-405.

ISTA (International Seed Testing Association) (1993) International rules for seed testing 1993. Seed Science and Technology 21, 25-30, 37-41.

Kranner, I. and Grill, D. (1996) Significance of thioldisulfide exchange in resting stages of plant development. Botanica Acta 109, 8-14.

Leprince, O., Atherton, N.M., Deltour, R. and Hendry, G.A.F. (1994) The involvement of respiration in free radical processes during loss of desiccation tolerance in germinating Zea mays L. - an electron paramagnetic study. Plant Physiology 104, 1333-1339.

Leprince, O., Deltour, R., Thorpe, P.C., Atherton, N.M. and Hendry, G.A.F. (1990) The role of free radicals and radical processing systems in loss of desiccation tolerance in germinating maize (Zea mays L.). New Phytologist 116, 573-580.

Magill, W., Deighton, N., Pritchard, H.W., Benson, E.E. and Goodman, B.A. (1993) Physiological and biochemical studies of seed storage parameters in Carica papaya. Proceedings of the Royal Society of Edinburgh, Section B 102, 439-442.

Maithani, G.P., Bahuguna, V.K., Rawat, M.M.S. and Sood, O.P. (1989) Fruit maturity and interrelated effects of temperature and container on longevity of neem (Azadirachta indica) seeds. Indian Forester 115, 89-97.

Navari-Izzo, F., Meneguzzo, S., Loggini, B., Vazzana, C. and Sgherri, C.L.M. (1997) The role of the glutathione system during dehydration of Boea hygroscopica. Physiologia Plantarum 99, 23-30.

Pammenter, N.W. and Berjak, P. (1999) A review of recalcitrant seed physiology in relation to desiccationtolerance mechanisms. Seed Science Research 9, 13-37.

Ponnuswamy, A.S., Vinaya Rai, R.S., Surendran, C. and Karivaratharaju, T.V. (1990) Studies on maintaining seed longevity and the effect of fruit grades in neem (Azadirachta indica). Journal of Tropical Forest Science 3, 285-290.

Poulsen, K. (1996) Case study of neem (Azadirachta indica) seeds. pp. 101-104 in Ouédraogo, A.S.; Poulsen, K.; Stubsgaard, F. (Eds) Improved methods for the handling and storage of intermediate/recalcitrant tropical forest tree seeds. Rome, International Plant Genetic Resources Institute (IPGRI).

Priestley, D.A. and Leopold, A.C. (1979) Absence of lipid oxidation during accelerated aging of soybean seeds. Plant Physiology 63, 726-729.

Roberts, E.H. (1973) Predicting the storage life of seeds. Seed Science and Technology 1, 499-514.

Roberts, E.H. and Ellis, R.H. (1989) Water and seed survival. Annals of Botany 63, 39-52.

Sanhewe, A.J. and Ellis, R.H. (1996a) Seed development and maturation in Phaseolus vulgaris. I. Ability to germinate and to tolerate desiccation. Journal of Experimental Botany 47, 949-958.

Sanhewe, A.J. and Ellis, R.H. (1996b) Seed development and maturation in Phaseolus vulgaris. II. Post-harvest longevity in air-dry storage. Journal of Experimental Botany 47, 959-965.

Sacandé, M., Buitink, J. and Hoekstra, F.A. (2000) A study of water relations in neem (Azadirachta indica) seed that is characterised by complex storage behaviour. Journal of Experimental Botany 51, 635-643.

Sacandé, M., Hoekstra, F.A., Van Pijlen, J.G. and Groot, S.P.C. (1998) A multifactorial study on conditions influencing storage longevity of neem (Azadirachta indica) seeds. Seed Science Research 8, 473-482.

Sacandé, M., Van Pijlen, J.G., De Vos, C.H.R., Hoekstra, F.A., Bino, R.J. and Groot, S.P.C. (1996) Intermediate storage behaviour of neem tree (Azadirachta indica) seeds from Burkina Faso. pp. 101-104 in Ouédraogo, A.S.; Poulsen, K.; Stubsgaard, F. (Eds) Improved methods for the handling and storage of intermediate/recalcitrant tropical forest tree seeds. Rome, International Plant Genetic Resources Institute (IPGRI).

Senaratna, T. and McKersie, B.D. (1986) Loss of desiccation tolerance during seed germination: a free radical mechanism of injury. pp. 85-101 in Leopold, A.C. (Ed.) Membranes, metabolism and dry organisms. Ithaca, NY, Cornell University Press.

Senaratna, T., Gusse, J.F. and McKersie, B.D. (1988) Ageinduced changes in cellular membranes of imbibed soybean seed axes. Physiologia Plantarum 73, 85-91. 
Sinniah, U.R., Ellis, R.H. and John, P. (1998) Irrigation and seed quality development in rapid-cycling brassica: soluble carbohydrates and heat-stable proteins. Annals of Botany 82, 647-655.

Steadman, K.J., Pritchard, H.W. and Dey, P.M. (1996) Tissue-specific soluble sugars in seeds as indicators of storage category. Annals of Botany 77, 667-674.

Sun, W.Q. (1997) Glassy state and seed storage stability: The WLF kinetics of seed viability loss at $T-T_{\mathrm{g}}$ and the plasticization effect of water on storage stability. Annals of Botany 79, 291-297.

Tompsett, P.B. and Kemp, R. (1996) Database of tropical tree seed research, with special reference to the Dipterocarpaceae, Meliaceae and Araucariaceae: database contents. pp. 1-263. Wakehurst Place, Ardingly, Royal Botanic Gardens.

Van Bilsen, D.G.J.L. and Hoekstra, F.A. (1993) Decreased membrane integrity in aging Typha latifolia L. pollen: accumulation of lysolipids and free fatty acids. Plant Physiology 101, 675-682.

Van Bilsen, D.G.J.L., Van Roekel, T. and Hoekstra, F.A. (1994) Declining viability and lipid degradation during pollen storage. Sexual Plant Reproduction 7, 303-310.
Wilson, D.O. and McDonald, M.B. (1986) The lipid peroxidation model of seed ageing. Seed Science and Technology 14, 269-300.

Wolkers, W.F., Tetteroo, F.A.A., Alberda, M. and Hoekstra, F.A. (1999) Changed properties of the cytoplasmic matrix associated with desiccation tolerance of dried carrot somatic embryos. An in situ Fourier transform infrared study. Plant Physiology 120, 153-163.

Wolkers, W.F., Van Kilsdonk, M.G. and Hoekstra, F.A. (1998) Dehydration-induced conformational changes of poly-L-lysine as influenced by drying rate and carbohydrates. Biochimica et Biophysica Acta 1425, 127-136.

Received 10 January 2000

accepted after revision 28 April 2000

(c) CAB International, 2000 